\title{
A comparison of different Artificial Intelligence and Machine Learning methods for Gully Erosion Susceptibility Mapping in the Upper Narmada Basin
}

Vinay Raikwar ( $\nabla$ vinay.utd@gmail.com )

Government Mahatama Gandhi Smrati PG College Itarsi Hoshangabad Madhya Pradesh India https://orcid.org/0000-0002-5020-834X

Pramod Pagare

Government Mahatama Gandhi Smarti PG College Itarsi Hoshangabad Madhya Pradesh

Aminu Abdulwahab

Federal Polytechnic Mubi PMB 35 Adamawa State

Vikram Agone

SSVPS Science College Dhule Maharastra

Priyank Pravin Patel

Presidency University Kolkata

\section{Research Article}

Keywords: Gully erosion, artificial intelligence, susceptibility mapping, machine learning, soil loss

Posted Date: March 11th, 2021

DOI: https://doi.org/10.21203/rs.3.rs-303397/v1

License: (c) (i) This work is licensed under a Creative Commons Attribution 4.0 International License.

Read Full License 


\section{Abstract}

Gully erosion (GE) is one of the most important mechanisms of soil loss worldwide. In this study, various machine learning techniques such as Classification and Regression Trees (CART), Random Forest (RF) and Artificial Neural Networks (ANN), have been used to ascertain gully erosion susceptibility (GES) in the Upper Narmada Basin (UNB). The mapping and analysis was achieved using R programming and ArcGIS 10.8 software. Initially, a gully inventory map (GIM) of 1501 gully locations was prepared from Sentinel-2 and Google Earth images and extensive field surveys. Out of the 1501 gullies in the study area, 1051 gully locations (about 70\%) were used for training and 450 gully locations (about $30 \%$ ) were used for validating the models. For GES modeling, 12 gully conditioning factors (GCFs) were used and the relationships between these GCFs and gully erosion were evaluated. The GES maps were prepared using the CART, RF and ANN models and divided into three susceptibility-based classes: low, moderately and highly susceptible GE classes. A large part of the study area was found to be highly susceptible to GE. Subsequent validation tests proved the high efficacy of these models in ascertaining the GES. The RF model was found to perform best compared to the others in this respect with an AUC-ROC value of 0.78 . This model can therefore be used not only in the UNB but in other such areas to evaluate the GES zones and thereby aid in framing suitable measures to mitigate soil loss through gully erosion.

\section{Highlights}

- Gully erosion susceptibility was assessed using multiple machine learning models.

- Twelve input layers of different parameters were prepared for the analysis.

- Classification and Regression Tree, Random Forest \& Artificial Neural Network used.

- Low, moderate and high gully erosion susceptibility zones were demarcated.

- Random Forest model shown to be the most accurate in the accuracy analysis.

\section{Introduction}

Soils are a significant biodiversity carrier that sustains vital human needs (Keesstra et al., 2016) and their persistent worldwide deterioration has been a long-standing problem (Magliulo, 2012), adversely affecting lives and livelihoods (UNEP, 2017; Haregeweyn et al., 2017). Soil erosion through gullies is a common occurrence (Nampak, 2018; Amiri et al., 2019), with such narrow, incised channels being pathways for the surface runoff channelization (Kirkby and Bracken, 2009) that leads to substantial landscape degradation (Marzolff and Ries, 2011; Borrelli et al., 2017). This causes loss of a vital natural resource and therefore studies of gully formation and analysis of their causative factors have gained much precedence (Castillo and Gomez, 2016). Gully erosion can foster various environmental issues, such as desertification, floods, lowered soil fertility and agricultural productivity decline, which have a detrimental effect on the local economy (Zhang et al., 2018; Zabihi et al., 2018). The factors enabling gully erosion are generally twofold- physiographic (which encapsulates the region's lithology, topography, soil and climatic attributes) and anthropogenic (comprising of its land use and land cover, land 
management practices and built infrastructure) (Cui et al., 2012; Tang et al., 2013; Castillo and Gomez, 2016; Malik, 2008). This process ensues when the geomorphological threshold value of an area is surpassed by water erosion or sediment formation (Mccloskey et al., 2016).

Gully erosion thus raises the runoff coefficient by changing surface roughness, removing the topsoil and reducing ground permeability, thereby altering the hydrological characteristics of a region (Rahmati et al., 2016). It also affects the production of sediments in upstream areas, river flow conditions and water quality, the effectiveness/maintenance of water transfer structures and the storage of downstream surface water (Rahmati et al., 2017; Pourghasemi et at., 2017; Renschler and Harbor, 2002). Climatic changes can also contribute to the rise of gullies, following subsequent changes in the local groundwater balance (Conforti et al., 2011; Luca et al., 2011). As continual gully erosion can severely affect agricultural prospects and enhance wasteland expansion (Deng et al., 2015; Prosdocimi et al., 2016), a range of methods have been employed to track their growth and how the ambient landscape attributes enable this process to occur (e.g. Yitbarek et al., 2012; Conoscenti et al., 2013; Desprats et al., 2013; Shruthi et al. 2015), in order to demarcate the most susceptible zones where new gullies can form (Gomez-Gutierrez et al., 2015). The use of geospatial datasets and methods for this purpose is now widespread (e.g. Liu et al., 2016; Goodwin et al., 2017; Bennett and Wells, 2019), along with the infusion of various statistical measures and algorithms that facilitate such analysis and provide accuracy assessments of the generated outputs (El Baroudy and Moghanm, 2014; Bianchin et al., 2016).

In such susceptibility studies, discerning the spatial distribution of gullies becomes important along with the undertaking of a sensitivity analysis of its causative factors (Kirkby and Bracken, 2009; Luca et al., 2011), which analyses the diversity of these attributes (Rahmati et al., 2017; Hosseinalizadeh et al., 2019; Zakerinejad and Maerke, 2015) and the differences in their relative contribution towards enabling gully formation (Agharazi et al., 2017; Conoscenti et al., 2014). Through this, gully erosion susceptibility maps can be derived, which highlight areas where such features are most likely to develop (Dewitte et al., 2015). While, these investigations have been mostly geoinformatics-based (Sadeghi-Niaraki et al., 2010; Faroqi and Sadeghi-Niaraki, 2016), the recent development of different machine learning algorithms and the integration of geographic information systems (GIS) with the R programming language has facilitated more precise susceptibility model preparation (Arabameri et al., 2019; Hosseinalizadeh et al., 2019). These machine learning methods based on the $\mathrm{R}$ programming language are also considered to be more computationally efficient and accurate (Hosseinalizadeh et al., 2019; Zakerinejad and Maerke, 2015; Pourghasemi et al., 2017; Arabameri et al., 2018) and thus their outputs can be better used for framing soil loss amelioration schemes. Some of the more common techniques used to generate these GIS-based Gully Erosion Susceptibility Maps (GESMs) are Artificial Neural Networks (ANN) (Tsangaratos and Benardos, 2014; Rahmati et al., 2017), support vector machines (Conforti et al., 2011), lofE (Zabihi et al., 2018), Frequency Ratio (FR) (Conforti et al., 2011; Rahmati et al., 2016; Zabihi et al., 2018), Analytic Hierarchy Process (Sela et al., 2012), Multivariate Adaptive Regression Splines (MARS) (Gutierrez et al., 2009), Weight of Evidence (Dube et al., 2014; Zabihi et al., 2018), Random Forest (RF) (Rahmati et al., 2017), ensemble machine learning models (Arabameri et al., 2019; Gayen et al., 2019) and logistic regression (LR) (Akgün and Türk, 2011; Dewitte et al., 2015). 
Since susceptibility assessments depend on a number of diverse factors, statistical approaches, especially particular multivariate techniques, are clearly relevant for obtaining quantitative forecasts of potential event locations of such natural hazards (Luca et al., 2011). In this regard, ANN, Boosted Regression Tree (BRT), MARS and Generalized Linear Model (GLM) techniques have contributed significantly to the field of susceptibility mapping, most notably in landslide hazard assessments and gully erosion studies (Vorpahl et al., 2012; Confortiet al., 2014; Youssefet al., 2016; Gomez-Gutierrez et al., 2015; Pourghasemiet at., 2017; Rahmati et al., 2017). Such machine learning based models are beneficial since- (a) the dependent variable is dichotomous (i.e. 0 or 1 ) and the expected values can be expressed as a probability; (b) various types of independent variables can be used, such as categorical, ordinal and continuous binary variables; (c) no preliminary assumptions need to be described before they are used; and (d) the independent variables, when used in these models, do not necessarily need to have normal distributions (Luca et al., 2011; Rahmati et al., 2017).

Given the widespread use of machine learning algorithms (MLA) for gully erosion susceptibility analysis, we have undertaken a comparison of some of the most common methods employed, using the Upper Narmada Basin (UNB) in western India as a case study. This provides an insight into which of these methods is more apt for this purpose. We therefore aim to-

- Assess the different environmental factors that abet the occurrence of gullies in the test region.

- Explore the efficacy and robustness of various susceptibility models in predicting gully erosion zones.

To prepare the above GESM outputs for each model tested on the UNB, firstly sites of the existent gullies in the area shall be mapped. Alongside this, the respective layers of the different causative factors associated with gully erosion (as ascertained from the literature) shall be prepared from various geospatial datasets. Different machine learning models will then be calibrated and trained using the above database and executed to predict the gully erosion susceptibility in the area. Subsequently, statistical measures shall be enumerated to gauge these models' effectiveness and accuracy, and their respective outputs shall be compared with the actual gully sites in the area for validation. The primary objective of this analysis would thus be to prepare a GESM for the use of RBF-ICA models from the LR, RF and ensemble models. The novelty of this study lies in its refinement of the process of RBF interpolation by including a susceptibility map of gully erosion using the ICA algorithm.

\section{The Study Area}

The Narmada River is known as the lifeline of the central Indian state of Madhya Pradesh and it is the largest westward flowing river in the country. It rises in the Amarkantak Plateau of the Maikal Range in Anuppur District of Madhya Pradesh at a height of $1057 \mathrm{~m}$ above sea level and travels $1312 \mathrm{~km}$ to outfall into the Gulf of Khambhat in the Arabian Sea, near Bharuch in Gujarat. The Central Water Commission divides its basin, which lies hemmed in between the Vindhyachal and Satpura Ranges, into three partsUpper, Middle and Lower Narmada basin. The Upper Narmada Basin (UNB) comprises of a fairly large 
tract lying between $21^{\circ} 41 \rrbracket \mathrm{N}$ to $23^{\circ} 46 \rrbracket \mathrm{N}$ and $79^{\circ} 17 \nabla \mathrm{E}$ to $81^{\circ} 46 \nabla \mathrm{E}$ (Fig. 1). It covers an area of 23089 sq.km ( $23.37 \%$ of the overall basin area) and its perimeter is $1652.20 \mathrm{~km}$. The longitudinal basin length $(\mathrm{L})$ is $258.40 \mathrm{~km}$ and the highest and lowest points within the UNB are at $1135.73 \mathrm{~m}$ and $328.74 \mathrm{~m}$, respectively, above mean sea level. The UNB has a humid tropical climate, receiving on average an annual rainfall amount of $1178 \mathrm{~mm}$, while the annual average temperature is $25.80^{\circ} \mathrm{C}$. About $30.83 \%$ of its area is under forest cover, $57.81 \%$ under arable land and $6.26 \%$ is grassland/wastelands.

\section{Materials And Methods}

For this study, diverse datasets were gathered together or generated from different sources (Table 1). Image analysis was undertaken on the Google Earth Engine platform on Sentinel-2 (MSI Multispectral Instrument, Level 1C) images of spatial resolution $10 \mathrm{~m}$ of the area and a Shuttle Radar Topographic Mission (SRTM) digital elevation model (DEM) of spatial resolution $30 \mathrm{~m}$ was used to extract the terrain attributes. The study followed the following steps (Figure 2):

\section{Table 1: Different gully erosion conditioning factors}




\begin{tabular}{|c|c|c|c|c|}
\hline Attribute & Factors & Data source & $\begin{array}{l}\text { Data } \\
\text { Resolution }\end{array}$ & Classification \\
\hline \multirow[t]{3}{*}{ Topographic } & Elevation & \multirow[t]{3}{*}{ SRTM DEM } & \multirow[t]{3}{*}{$30 \mathrm{~m}$} & Manual \\
\hline & Slope & & & \\
\hline & Aspect & & & Azimuth \\
\hline \multirow[t]{3}{*}{ Physiographic } & Lithology & \multirow[t]{2}{*}{ Geological Survey of India } & \multirow[t]{2}{*}{$1: 250,000$} & Lithology type \\
\hline & Geomorphology & & & $\begin{array}{l}\text { Geomorphology } \\
\text { type }\end{array}$ \\
\hline & Soil class & $\begin{array}{l}\text { Soil and Land Use Survey } \\
\text { of India (SLUSI) }\end{array}$ & $1: 50,000$ & Soil type \\
\hline \multirow[t]{2}{*}{ Hydrological } & Rainfall & $\begin{array}{l}\text { Climate Hazards Group } \\
\text { InfraRed Precipitation with } \\
\text { Station data (CHIRPS } \\
\text { Pentad 2.0) }\end{array}$ & $\begin{array}{l}0.05 \\
\text { degrees }\end{array}$ & \multirow[t]{2}{*}{ Natural breaks } \\
\hline & Drainage density & SRTM DEM & $30 \mathrm{~m}$ & \\
\hline \multirow[t]{2}{*}{ Vegetation } & $\begin{array}{l}\text { Land use and land } \\
\text { cover }\end{array}$ & $\begin{array}{l}\text { Copernicus Global Land } \\
\text { Cover Layers: CGLS-LC100 } \\
\text { Collection } 2\end{array}$ & $10 \mathrm{~m}$ & Land use type \\
\hline & $\begin{array}{l}\text { Normalized } \\
\text { Difference } \\
\text { Vegetation Index } \\
\text { (NDVI) }\end{array}$ & $\begin{array}{l}\text { Sentinel-2 MSI } \\
\text { Multispectral Instrument, } \\
\text { Level 1C }\end{array}$ & $10 \mathrm{~m}$ & Natural breaks \\
\hline Anthropogenic & Road density & $\begin{array}{l}\text { From analysis of Sentinal-2 } \\
\text { images }\end{array}$ & $10 \mathrm{~m}$ & Natural breaks \\
\hline Locational & $\begin{array}{l}\text { Stream-road } \\
\text { junctions and sites } \\
\text { of existing gullies }\end{array}$ & Google Earth & & \\
\hline
\end{tabular}

Source: Compiled by the authors

i. Preparation of data layers for the gully inventory map (GIM) and gully conditioning factors (GCFs).

ii. Examination of the interlinkages between the GIM and individual GCFs.

iii. Application of machine learning models [Classification and Regression Trees (CART), RF and ANN] to prepare the gully erosion susceptibility maps (GESMs).

\subsection{Gully Inventory Map}

The Gully Inventory Map (GIM) is important since it enables the different predictive models to prepare the gully erosion susceptibility maps (GESMs) (Hosseinalizadeh et al., 2019). The GIM layer was considered to be the dependent variable in this analysis. Gully locations were initially ascertained from the Google Earth Engine platform and verified in the field using a handheld global positioning system (GPS) device. 
In the study area, a total number of approximately 1501 gullies were found, from which 1051 gully locations (about $70 \%$ ) were used for the model training purpose and 450 gully locations (about $30 \%$ ) were used for validating their respective outputs.

\subsection{Gully Erosion Conditioning Factors}

A significant step in the preparation of GESMs is the initial choice of geo-environmental factors (Hosseinalizadeh et al., 2019), which are then analyzed by different machine learning algorithms. Based on the existent literature, twelve gully erosion conditioning factors (GCFs) were chosen (Table 1). These were the area's elevation, slope amount, slope aspect, soil cover, geomorphology, lithology, land use and land cover (LULC), Normalized Difference Vegetation Index (NDVI), annual rainfall, stream density and road density (Figure 3a, 3b, 3c). Another layer with the junctions of streams and roads and existing large gullied tracts was also prepared, as newer gullies are more prone to form near such locations (Gayen et al., 2019; Hosseinalizadeh et al., 2019).

The altitude of an area primarily influences gully erosion and also affects vegetation and precipitation (Zhu et al., 2014; Gomez-Gutierrez et al., 2015). It also regulates the drainage flow and markedly influences the moisture content of the soil and the hillside slope attributes (Rahmati et al., 2017). Both, the slope amount and its direction, have a major impact on gully erosion, in terms of channeling the surface runoff (Arabameri et al., 2019). The slope map of the UNB was extracted from the SRTM DEM using the relevant algorithms provided in the ArcGIS toolbox and this was also classified into five zones. The aspect map (similarly prepared from the SRTM dataset), was classified into ten sub-classes on the basis of the principal directions.

Due to its direct effects on the rock erodibility, soil character and infiltration rate (Casalı, et al., 1999), the ambient lithology is one of the most important input layers when modeling gully erosion susceptibility. Along with the lithology, the local geomorphology (both natural and human-made landforms) plays a vital role in conditioning gully erosion (Gayen et al., 2019). Both these layers were prepared from the Geological Survey of India databases and maps for the same. Another important factor governing infiltration and thereby runoff generation for surface erosion is the local soil properties (Hosseinalizadeh et al., 2019). This layer was prepared from the Soil and Land Use Survey of India (SLUSI) data products for this region.

The annual rainfall map of the UNB was prepared on the basis of rainfall data collected from CHIRPS Pentad 2.0 (https://www.chc.ucsb.edu/data/chirps) using the kriging interpolation method in ArcGIS. The stream network layer was extracted from the DEM using the D8 flow routing and flow accumulation algorithms available in ArcGIS and for calculating the drainage density, the line density tool was used. The type of land use and land cover (LULC) greatly impacts on erosional processes. Barren areas typically undergo more rapid erosion than forest-covered surfaces (Dai et al., 2001). Using the maximum likelihood classification method, the LULC map of the UNB was derived from the Sentinel-2 images used (Copernicus Global Land Cover Layers: CGLS-LC100 Collection 2). Alongside the extent of the ambient vegetation cover, its robustness/health is a pertinent factor that influences the amount of precipitation 
intercepted and lost through evapotranspiration, thereby reducing the amount available for runoff. To gauge the vegetation health in the UNB, the NDVI parameter was ascertained as follows:

$N D V I=I R-R / I R+R($ Eq. 1)

where, IR is the infrared portion of the electromagnetic spectrum and $\mathrm{R}$ is the red portion of the electromagnetic spectrum. NDVI values range between +1 (healthy vegetation) and -1 (non-vegetation class). A road density layer was incorporated since road construction often results in forest clearance and slope modification, which can then facilitate runoff channelization and gully initiation. The main road networks were digitized and distance buffers created around them in ArcGIS, using the relevant tools. The junctions of the main roads and streams and the already gullied tracts were extracted through digitization. The principal contours and their alignment/pattern were also demarcated in this layer to highlight the broad physiographic entities within the UNB.

All the above input layers are made similar in terms of their locational reference information and a uniform cell size of $10 \mathrm{~m}$ for the ensuing analyses (following similar procedures adopted by Rahmati et al., 2017; Gayen et al., 2019; Hosseinalizadeh et al., 2019).

\subsection{Machine Learning Methods}

\subsubsection{Classification and regression trees (CART)}

CART (Breiman et al., 1984 is a common technique of data mining based on recursive binary partitioning and was developed as a MLA using R software (Breiman et al., 2017). However, only a few GESM studies have employed it (Akgün and Türk, 2011). By repeated partitioning of nodes from which the data is partitioned, CART models are acquired until the values are either identical or limited to fewer observations than the user-defined boundaries (Naghibi and Pourghasemi, 2015; Youssef et al., 2016). Monotonic alteration and dissimilar factor scales (Aertsen et al., 2011; Naghibi and Pourghasemi, 2015; Youssefet al., 2016; Akgün and Türk, 2011) remain unaltered in the model. Additionally, the pruning method helps prevent problems relating to over-fitting and the exclusion of irrelevant data (Akgün and Türk, 2011). Here, a selection rule called the modified towing rule, based on a straightforward relationship between the distribution of the target function in two child nodes data (Akgün and Türk, 2011), was used as follows:

$I($ Split $)=\left[0.25(q(1 \otimes \mathrm{s} q))^{\mathrm{u}} P L(k) \otimes P R(k)\right]^{2}($ Eq. 2$)$

where, $k$ denotes the target parameter, the probability distributions of the left and right child nodes are indicated separately by $P L(k)$ and $P R(k)$ and u specifies the penalty imposed on partitions that generate two conflicting child nodes (Wu et al., 2008). The result of CART is a binary decision tree dividing the prediction space into regions $(R m)$, where the response factor values are homogeneous $\left(\cong \mathrm{a}_{m}\right)$, as follows: 


\section{$f(x) \cong a_{m} ; \forall x \in R_{m} \quad$ (Eq. 3$)$}

In R 3.6.0 (Therneau et al., 2019), the CART model is implemented using the 'rpart' package.

\subsubsection{Random Forest (RF)}

Random forest MLAs have emerged from the random forest decisions first suggested by Ho (1995) and then Breiman (2001). RF has been recognized as a rapid learning algorithm and has recently been validated in a number of GESM studies (Rahmati et al., 2017; Arabameri et al., 2019; Gayen et al., 2019) due to its unbiased classification and selection without deletion of a large number of input variables (Immitzer et al., 2012). RF is also commonly used for questions related to regression and classification (Rahmati et al., 2017). In order to create a set of decision trees with regulated variance, the approach incorporates Breiman's bagging idea (i.e. bootstrap aggregation- Breiman, 2001) and the random selection of features, implemented independently (Ho, 1998; Amit and Geman, 1997). This algorithm generates numerous decision trees that form a forest, altering the factors that disturb the target and generating aggregations to provide accurate results (Arabameri et al., 2019). Each tree is built using the CART technique on the basis of a bootstrapped sample of data with a random subset of variables selected at the individual node, with the final model prediction ascertained using the decision trees of all majority votes (Micheletti et al., 2014; Liaw and Wiener, 2002). The key benefits of the RF approach compared to other MLA are discussed in Naghibi and Pourghasemi (2015). Inputs are given for the number of trees ( $\mathrm{t}$ ) and factors ( $\mathrm{n}$ ) used in the RF (Gayen et al., 2019). It utilizes the mean accuracy of decrease and the mean Gini index of decrease in the ranking of factors. The RF algorithm expression is provided in Hastie et al. (2009).

\subsubsection{Artificial Neuron Network (ANN)}

ANN is a machine learning system that is generally used to solve different classification and prediction difficulties and is a particular type of nonlinear regression based on a collection of connected neurons or computational units (De la Rosa et al., 1999). It is a method of input data training that identifies a pattern of performance, i.e. the aim that has been determined by its ability to learn. Several researchers have carried out surface erosion analysis using ANN and have obtained acceptable accuracy predictions (Negnevitsky, 2002; Kim and Gilley, 2008). The most common form of ANN algorithm is the multi-layer perceptron (MLP) (Negnevitsky, 2002). The MLP consists of three-layers of neurons (nodes or processing elements) comprising the input layer, hidden layer and the output layer. Based on the corresponding weights, the neurons or nodes in the hidden layer analyze a significant amount of information from their inputs (i.e. the conditioning factors) (Lee et al., 2003) and the input layer uses a nonlinear transfer function to obtain a probabilistic estimate of the occurrence of the dependent parameters. The eventual output layer consists of a susceptibility map (Pourghasemi et at., 2017). The secret and output layers thus receive data from the input layer and evaluate complex functions in order to boost the model's generalizability and predictive influence (Falaschi et al., 2009). The numbers of input and output nodes 
are fixed using a design application in order to use an ANN to generate a GESM. In fact, the input nodes are equal to the control factors and the output nodes are the pairs of values for each pixel for the dependent variable or gully erosion (between 0 and 1 ), where ' 1 ' denotes the highest likelihood of gully erosion and ' 0 ' denotes no such erosion. We have used a feed forward implementation of ANN with a single hidden layer in this analysis (Figure 4). In this form of ANN, the two key control parameters, comprising the amount of weight decay and the number of units or neurons in the hidden layer (Vorpahl et al., 2012), were selected using the 'train' function in the 'caret' package (Kuhn, 2008) by a tenfold internal cross-validation process. The ANN model was implemented using the 'nnet' package (Ripley and Venables, 2016) in R software v.3.4.1.

\section{Results And Discussion}

\subsection{Spatial distribution of the causative factors}

The prepared UNB elevation map from the SRTM DEM was classified into five zones. The elevation range was $807 \mathrm{~m}$ (highest $1136 \mathrm{~m}$, lowest $329 \mathrm{~m}$ ). Higher elevations were evident towards the UNB's eastern margins while the landscape graded down to the basin outlet in the west. The elevation map also clearly highlighted the principal valleys in the UNB, which trended from east to west. Most of the basin area has gentler slopes $\left(\sim 0^{\circ}\right.$ to $\left.2.75^{\circ}\right)$ but marked breaks-of-slope were evident along the valley sides in the central and eastern part of the study area. The highest slope values of $\sim 58^{\circ}$ were noted along the escarpments traversing the eastern side. The aspect map showed a dominance of flat slope segments throughout the basin. Following the trend of the main drainage lines, many slopes segments dip towards the west and southwest. Due to the presence of steep escarpments, local variations in the slope aspect are seen on opposing flanks of the ridges.

Being a part of India's peninsular block, the UNB is mostly covered in basaltic lava flows (basic volcanics) and the associated crystalline rock types (metamorphics and other plutonic intrusives). In all, there are seven rock groups present in the UNB. Patches of sedimentary rocks and unconsolidated sediments are found in the principal river valleys at lower elevations towards the west. The UNB has a wide variety of landform types, which range from denudational to structural ones. Fluvial depositional features are more evident to the west while in the higher elevation and steeper slope sections to the east, there is a preponderance of structural landforms and residual, dissected landscapes. Human-made landforms like mine dumps are also present in the area. The prepared soil map of the UNB had six categories based on the ambient soil types- deep black soils, laterite soil, medium black soil, red loamy soil, red sandy soil and shallow clay soil. Deep black soils, which can retain much moisture, are only seen within the main valleys and floodplains towards the west, while most of the dissected plateau and ridge areas contain shallow soils. Leaching in the higher elevation zones in the east has resulted in the formation of laterite soils.

The rainfall amount varies from about $176 \mathrm{~cm}$ near the southern fringe of the basin to $138 \mathrm{~cm}$ near its northern extremities. Drainage density values are on the lower side (highest values of $0.44 \mathrm{~km} / \mathrm{sq} . \mathrm{km}$ are seen in various stream confluence zones). The main LULC components found were water bodies, 
agricultural lands, forests/dense vegetation, shrubs and built-up tracts. Forests and agricultural lands were the dominant classes. The only significant built-up patch was present in the western part of the UNB (the town of Jabalpur), near which is present the Bargi Reservoir on the Narmada River. The dissected plateau tracts and hill ranges in the eastern part of the UNB reported the highest NDVI values of about 0.74. These roads converge on Jabalpur town, located in the western part of the UNB. The junctions of the main roads and streams and the already gullied tracts were extracted through digitization. The broad physiographic entities present in the UNB (floodplains, pediments, ridges, scarps and dissected plateau surfaces), generally followed the local elevation variation.

\subsection{Spatial Gully Erosion Susceptibility Analysis}

Each of the GESM susceptibility outputs (Fig. 5a, 5b) obtained from the CART, RF and ANN models predicted $n$ presences: 300 , i.e. 300 gullies as gullies and $n$ absences: 200 , i.e. 200 non-gullies (Table 2). Based on their ROC-AUC values that ranged from 0.616625 to 0.781775 (Fig. 6, Table 2), all the three models could be said to have been mostly successful in predicting likely gully erosion locations in the UNB. Their respective accuracies were $61.66 \%$ for the CART, $78.17 \%$ for the RF and $65.75 \%$ for the ANN model. The RF model was thus by far the best predictor of the likely gully erosion sites in the study area and also displayed a much higher precision. The ANN model performance was also acceptable as its accuracy was above $65 \%$.

Table 2

Model class and accuracy evaluation

\begin{tabular}{|lllllll|}
\hline SI. No. & Model & $\mathbf{n}$ presences & $\mathbf{n}$ absences & AUC & cor & max TPR + TNR at \\
\hline 1 & CART & 300 & 200 & 0.616625 & 0.1706724 & 0.2311812 \\
\hline 2 & RF & 300 & 200 & 0.781775 & 0.3886573 & 0.7647333 \\
\hline 3 & ANN & 300 & 200 & 0.6575417 & 0.2539116 & 0.9324303 \\
\hline \multicolumn{5}{l}{ Source: Computed by the authors } \\
\hline
\end{tabular}


Table 3

Susceptibility classes denoted for the different model outputs

\begin{tabular}{|c|c|c|c|c|c|c|c|}
\hline \multirow[t]{2}{*}{$\begin{array}{l}\text { SI. } \\
\text { No. }\end{array}$} & \multirow[t]{2}{*}{ Model } & \multicolumn{3}{|c|}{ Susceptibility value range } & \multicolumn{3}{|c|}{$\begin{array}{l}\text { Proportion of UNB in each class } \\
\text { (sq.km) }\end{array}$} \\
\hline & & Low & Medium & High & Low & Medium & High \\
\hline 1 & CART & $\begin{array}{l}0.0000- \\
0.1760\end{array}$ & $\begin{array}{l}0.0177- \\
0.4195\end{array}$ & $\begin{array}{l}0.4195- \\
0.9551\end{array}$ & 11306.47 & 7061.31 & 4665.92 \\
\hline 2 & RF & $\begin{array}{l}0.0004- \\
0.3868\end{array}$ & $\begin{array}{l}0.3868- \\
0.6263\end{array}$ & $\begin{array}{l}0.6263- \\
0.9856\end{array}$ & 6051.43 & 8692.70 & 8289.57 \\
\hline 3 & ANN & $\begin{array}{l}-0.5410- \\
0.3306\end{array}$ & $\begin{array}{l}0.3306- \\
0.7275\end{array}$ & $\begin{array}{l}0.7275- \\
1.4434\end{array}$ & 4815.99 & 5429.32 & 12788.40 \\
\hline 4 & $\begin{array}{l}\text { Mean of all the } \\
\text { models' outputs }\end{array}$ & $\begin{array}{l}-0.05329- \\
0.3061\end{array}$ & $\begin{array}{l}0.3061- \\
0.5549\end{array}$ & $\begin{array}{l}0.5549- \\
0.9537\end{array}$ & $7,391.30$ & $7,060.99$ & $8,581.30$ \\
\hline
\end{tabular}

On the basis of the relative importance accorded to the different input factors, both the CART and RF models highlighted the area's geomorphology (landforms), soil type (texture) and lithology as being the three most important variables that conditioned gully erosion in the region. The ANN model incorporated the LULC parameter within the list of the most important parameters, alongside those noted by the CART and RF models. These were followed by the other factors like road density, elevation, slope aspect, NDVI, precipitation, stream density and slope amount.

The individual GESM of the three models were all classified into high, moderate and low susceptibility zones (Fig. 5a, 5b), on the basis of the enumerated cell values (Table 3), using the natural breaks classification scheme (following Zhang, 2018). In each of the output GESM layers, the highest possibility of gully formation and erosion was noted in the central and eastern parts of the UNB, which lie within the dissected plateau and hill ranges that are comprised of basic volcanics or crystallines/metamorphics. This portion of the basin also has relatively higher elevation and is overlain by thin, shallow soils or laterite soils. Conversely, gullying possibilities are much lower in the western portion of the UNB, within the broader valley floors therein. A comparative analysis was carried out by overlaying the gully points used for the training and validation purposes on the delineated low, moderate and highly susceptible zones. Based on this (where the existing gully points coincided with the demarcated high susceptibility zones), likely areas of gully occurrence and absence were ascertained for each of the models.

Once the individual model outputs were obtained, two additional layers were made. The respective outputs of the CART, RF and ANN models were overlain together [Figure $5 \mathrm{~b}(\mathrm{~g})$ ] and displayed as a composite image by assigning the blue, green and red channels to them, respectively. The corresponding susceptibility values of each of their constituent cells were then averaged to derive a layer that represented the mean of all the models' outputs [Figure $5 b(h)]$.

\subsection{Model comparison}


The respective outputs of the three models used in this analysis, i.e. CART, RF and ANN, were categorized into zones of low, moderately and highly susceptible (GES) zones (Fig. 5a, 5b). When combined together

[Figure $5 \mathrm{~b}(\mathrm{~g})$ ], the ANN model shows the largest area of the highly susceptible zone while the CART model shows the largest area of the low susceptibility zone. Both these models have demonstrated quite acceptable prediction accuracy, according to the validation results (Fig. 6, Table 2). However, in terms of the AUC values, the RF model is the best with a score of $78.17 \%$, making it the most accurate, followed by the ANN model (65.75\%) and then the CART model (61.66\%). Therefore, relative to the other models, the RF model was better in predicting the GES zones in the UNB. In general, the results show that the area of the respective susceptibility groups decreased for all three models with increasing susceptibility (from low to high), whereas the area under gully erosion increased in contrast. These outcomes are in line with those obtained by Youssef et al. (2016).

By taking the RF model as the most accurate, the proportionate area under each of its three demarcated susceptibility classes (low, medium and high) were computed as being $26.27 \%, 37.74 \%$ and $35.99 \%$, respectively (Table 3) [the corresponding values for the CART model were $49.09 \%, 30.66 \%$ and $20.26 \%$, while these were $20.91 \%, 23.57 \%$ and $55.52 \%$ for the ANN model]. The RF model outputs of the above values are very close to that derived from the mean of all the models $(32.09 \%$ in the low susceptibility class and $30.66 \%$ and $37.26 \%$ in the medium and high susceptibility classes, respectively). Thus, it is of concern that more than one-third of the UNB can be subjected to gully erosion quite easily and that this process is quite likely to occur over two-thirds of the basin area (when considering the medium and high category coverage together).

\subsection{Discussion}

While numerous techniques have been developed and used worldwide for the spatial prediction of environmental hazards, the goal of all these methods is the same, i.e. to gauge the likely susceptibility of a place to that threat. The first step in controlling gully erosion is thus to assess the locations where this phenomenon can occur by preparing suitable GESMs, based on the existing locations of ambient gullied tracts and spatial distribution of the most likely erosion enhancing geo-environmental variables. The development of machine learning techniques during the last decade has furthered the preparation of seemingly more accurate susceptibility maps. For this, the input categorization, clustering and data elaboration are essential procedures (Mezaal et al., 2017; Rizeei et al., 2016).

To generate the GESMs for the UNB, based on the prepared training and validation datasets and 12 GCFs, we used the CART, RF and ANN MLAs. Landforms, soil type and lithology are the most influential and successful factors among all three models (CART, RF and ANN). These were followed by attributes like road density, elevation, aspect, NDVI, LULC, precipitation, stream density and slope, which had a comparatively lesser influence on the occurrence of gully erosion in the study area. We identified a highly susceptible class of GES in the central to eastern parts of the UNB and our results ranged from being quite accurate for the CART model to being very accurate for the RF model, based on their elicited AUC values. Very few such studies have been previously conducted in the headwater regions of the Narmada River, with more attention being paid to the neighboring Chambal and Godavari basins (e.g. Joshi and 
Nagare, 2013; Joshi, 2014; Pani, 2016; Ranga et al., 2016). Thus this paper fills an existing gap in the gully development landscape of the Indian Peninsula.

Some errors and limitations do exist in our study. The collection of gully locations in certain places within the affected area was quite less as these locations were difficult to access in the field while groundtruthing or were difficult to discern clearly from the images. Furthermore, the sampled gully dataset was split into a 70:30 ratio, following previous literature, without testing the sample accuracy. The topographic/landscape attributes derived from the DEM and images can be enumerated more precisely from higher resolution datasets (Erasmi et al., 2014; Pope et al., 2014; Das et al., 2016). In order to improve the accuracy of the GES models, the effective study of the non-gully area ratio, the assessment of the sample division, the consideration of the method for selecting the feature and the use of ensemble approaches are also helpful. At best, the ascertained GESMs highlight the broad zones wherein gullying can possibly take place, they are not indicative of individual sites of gully formation or growth, as such landform features are too minute to be detected from the range of datasets employed here. The tracking of the development of singular gullies and their associated landscape forms would be better achieved using close-range or aerial photogrammetry (Patel et al., 2020; Meinen et al., 2020).

\section{Conclusion}

The goal of this research was to not only analyze the ability of machine learning models to predict the susceptibility to gully erosion, but also to compare the ability and robustness of the models implemented, i.e. the CART, ANN and RF models. Results reveal that even when conducting model comparisons with some clear goals, such as prediction accuracy and robustness, the understanding of their strengths and limitations remains somewhat challenging for model preference. The RF obtained the most outstanding performance as per the achievements, based on evaluation criteria, while all three models indicated that the highest gully erosion susceptible zone is the central and eastern portion of the study area. Suitable land use planning measures are therefore required to avoid further gully and soil erosion in these tracts. Due to the high accuracy ascertained for the RF model, it can be employed not only in the Upper Narmada Basin for demarcating likely gullying affected zones, but in other areas too for similar assessments.

\section{Declarations}

Declaration of Interest Statement

No conflict of interest exists.

We wish to confirm that there are no known conflicts of interest associated with this publication and there has been no significant financial support for this work that could have influenced its outcome.

\section{References}


Aertsen, W., Kint, V., Van Orshoven, J., Muys, B., 2011. Evaluation of modelling techniques for forest site productivity prediction in contrasting ecoregions using stochastic multicriteria acceptability analysis (SMAA). Environ. Model. Softw. 26, 929-937.

Agharazi H, Davoudirad AA, Khosrobagi S, Shadfar S, Nikchah S, Najim A. 2017. Gully erosion Sufficiency mapping at Robatturk Watershed (Iran) using an artificial neural network model. Int J Comput Sci Netw Security (IJCSNS). 17(4):14.

Akgün A, Türk N. 2011. Mapping erosion susceptibility by a multivariate statistical method: a case study from the Ayvalık region, NW Turkey. Comput Geosci. 37(9):1515-1524.

Amiri, M.; Pourghasemi, H.R.; Ghanbarian, G.A.; Afzali, S.F. 2019. Assessment of the importance of gully erosion effective factors using Boruta algorithm and its spatial modeling and mapping using three machine learning algorithms. Geoderma, 340, 55-69.

Amit, Y., Geman, D., 1997. Shape quantization and recognition with randomized trees. Neural Computation 9, 1545-1588.

Arabameri A, Chen W, Loche M, Zhao X, Li Y, Lombardo L, Cerda A, Pradhan B, Bui DT. 2019. Comparison of machine learning models for gully erosion susceptibility mapping. Geosci Front.11 (21):2577.

Arabameri, A.; Pradhan, B.; Pourghasemi, H.R.; Rezaei, K.; Kerle, N. Spatial Modelling of Gully Erosion Using GIS and R Programing: A Comparison among Three Data Mining Algorithms. Appl. Sci. 2018, 8, 1369.

Bennett SJ, Wells RR. 2019. Gully erosion processes, disciplinary fragmentation, and technological innovation. Earth Surface Processes and Landforms 44: 46-53.

Bianchin S., Del Soldatto M, Solari L., Nolesini T, Pratesi F, Moretti S. 2016. Badland susceptibility assessment in Volterra municipality (Tuscany, Italy) by means of GIS and statistical analysis. Environ. Earth Sci 75: 889

Borrelli, P., Lugato, E., Montanarella, L., \& Panagos, P. 2017. A new assessment of soil loss due to wind erosion in European agricultural soils using a quantitative spatially distributed modelling approach. Land Degradation \& Development, 28(1), 335-344.

Breiman, L., 2001. Random forests. Mach. Learn. 45 (1), 5-32. https://doi.org/10.1023/ A:1010933404324.

Breiman, L., Friedman, J.H., Olshen, R.A., Stone, C.J., 1984. Classification and Regression Trees. Chapman and Hall, Boca Raton.

Breiman, L., Friedman, J.H., Olshen, R.A., Stone, C.J., 2017. Classification and Regression Trees. Routledge, New York. https://doi.org/10.1201/9781315139470. 
Casalı J, Lopez J, Giraldez J. 1999. Ephemeral gully erosion in southern Navarra (Spain). Catena. 36(12):65-84.

Castillo, C., \& Gómez, J. A. 2016. A century of gully erosion research: Urgency, complexity and study approaches. Earth-Science Reviews, 160, 300-319.

Conforti M, Aucelli PP, Robustelli G, Scarciglia F. 2011. Geomorphology and GIS analysis for mapping gully erosion susceptibility in the Turbolo stream catchment (Northern Calabria, Italy.). Nat Hazards. 56(3):881-898.

Conforti, M., Pascale, S., Robustelli, G., Sdao, F., 2014. Evaluation of prediction capability of the artificial neural networks for mapping landslide susceptibility in the Turbolo River catchment (northern Calabria, Italy). Catena 113, 236-250.

Conoscenti C, Agnesi V, Angileri S, Cappadonia C, Rotigliano E, Ma“rker M. 2013. A GIS-based approach for gully erosion susceptibility modelling: a test in Sicily, Italy. Environ Earth Sci 70(3):1179-1195

Conoscenti C, Angileri S, Cappadonia C, Rotigliano E, Agnesi V, M€arker M. 2014. Gully erosion susceptibility assessment by means of GIS-based logistic regression: a case of Sicily (Italy). Geomorphology. 204:399-411.

Cui, L., Pan, G., Li, L., Yan, J., Zhang, A., Bian, R., \& Chang, A. 2012. The reduction of wheat Cd uptake in contaminated soil via biochar amendment: a two-year field experiment. BioResources, 7(4), 5666-5676.

Dai F, Lee C, Li J, Xu Z. 2001. Assessment of landslide susceptibility on the natural terrain of Lantau Island, Hong Kong. Environ Geol. 40(3):381-391.

Das, S., Patel, P.P., Sengupta, S. 2016. Evaluation of different digital elevation models for analyzing drainage morphometric parameters in a mountainous terrain: a case study of the Supin-Upper Tons Basin, Indian Himalayas. Springerplus 5, 1544. https://doi.org/10.1186/s40064-016-3207-0

De la Rosa D, de la Mayol, F Lozano S 1999 An Expert System/Neural Network Model (impelERO) for Evaluating Agricultural Soil Erosion in Andalucia Region, Southern Spain. Agriculture, Ecosystem and Environment 73 pp 211-226.

Deng Q, Qin F, Zhang B, Wang H, Luo M, Shu C, Liu H, Liu G. 2015. Characterizing the morphology of gully cross-sections based on PCA: a case of Yuanmou Dry-Hot Valley. Geomorphology 228:703-713

Desprats, J.F. et al. 2013. Mapping linear erosion features using high and very high resolution satellite imagery. Land Degrad. Dev.24, 22-32.

Dewitte O, Daoudi M, Bosco C, Van Den Eeckhaut M. 2015. Predicting the susceptibility to gully initiation in data-poor regions. Geomorphology. 228:101-115. 
Dube F, Nhapi I, Murwira A, Gumindoga W, Goldin J, Mashauri D. 2014. Potential of weight of evidence modelling for gully erosion hazard assessment in Mbire District-Zimbabwe. Phys Chem Earth, Parts A/B/C. 67-69:145-152.

El Baroudy, A. A., \& Moghanm, F. S. 2014. Combined use of remote sensing and GIS for degradation risk assessment in some soils of the Northern Nile Delta, Egypt. The Egyptian Journal of Remote Sensing and Space Science, 17(1), 77-85.

Erasmi, S.; Rosenbauer, R.; Buchbach, R.; Busche, T.; Rutishauser, S. Evaluating the quality and accuracy of TanDEM-X digital elevation models at archaeological sites in the Cilician Plain, Turkey. Remote Sens. 2014, 6, 9475-9493. Sensors 2020, 20, 131325 of 25.

Falaschi, F., Giacomelli, F., Federici, P.R., Puccinelli, A., D'Amato Avanzi, G., Pochini, A., Ribolini, A., 2009. Logistic regression versus artificial neural networks: landslide susceptibility evaluation in a sample area of the Serchio River valley, Italy. Nat. Hazards 50, 551-569.

Faroqi H, Sadeghi-Niaraki A. 2016. GIS-based ride-sharing and DRT in Tehran city. Public Transp. 8(2):243-260.

Gayen A, Pourghasemi HR, Saha S, Keesstra S, Bai S. 2019. Gully erosion susceptibility assessment and management of hazard-prone areas in India using different machine learning algorithms. Sci Total Environ. 668:124-138.

Gomez-Gutierrez A', Conoscenti C, Angileri SE, Rotigliano E, Schnabel S (2015) Using topographical attributes to evaluate gully erosion proneness (susceptibility) in two Mediterranean basins: advantages and limitations. Nat Hazards 79: 291-314.

Goodwin NR, Armston JD, Muir J, Stiller I. 2017. Monitoring gully change: a comparison of airborne and terrestrial laser scanning using a case study from Aratula, Queensland. Geomorphology 282: 195-208.

Gutierrez AG, Schnabel S, Contador JFL. 2009. Using and comparing two nonparametric methods (CART and MARS) to model the potential distribution of gullies. Ecol Modell. 220(24):3630-3637.

Haregeweyn, N.; Tsunekawa, A.; Poesen, J.; Tsubo, M.; Meshesha, D.T.; Fenta, A.A.; Nyssen, J.; Adgo, E. Comprehensive assessment of soil erosion risk for better land use planning in river basins: Case study of the Upper Blue Nile River. Sci. Total Environ. 2017, 574, 95-108.

Hastie, T., Tibshirani, R., Friedman, J., 2009. Random forests. The Elements of Statistical Learning. Springer Series in Statistics. Springer, New York, pp. 587-604. https:// doi.org/10.1007/978-0-387-848587_15.

Ho, T., 1995. Random Decision Forest. 3rd Int'I Conf. on Document Analysis and Recognition, pp. 278282. 
Ho, T., 1998. The random subspace method for constructing decision forests. IEEE Transactions on Pattern Analysis and Machine Intelligence 20, 832-844.

Hosseinalizadeh, M.; Kariminejad, N.; Chen, W.; Pourghasemi, H.R.; Alinejad, M.; Behbahani, A.M.; Tiefenbacher, J.P. Gully headcut susceptibility modeling using functional trees, naïve Bayes tree, and random forest models. Geoderma 2019, 342, 1-11.

Immitzer, M., Atzberger, C., Koukal, T., 2012. Suitability of WorldView-2 data for tree species classification with special emphasis on the four new spectral bands. Photogramm. Fernerkund. Geolnf. (5), 573-588. https://doi.org/10.1127/1432- 8364/2012/0140, 2012

Joshi, V.U. 2014. Soil loss estimation by field measurements in the badlands along Pravara river (Western India). Journal of the Geological Society of India, 83, 613-624. https://doi.org/10.1007/s12594-014-00906

Joshi, V.U., Nagare, V.B. 2013. Badland formation along the Pravara River, Western Deccan, India. Can neotectonics be the cause? Zeitschrift fur Geomorphologie, 57(3), 349-370.

https://doi.org/10.1127/0372-8854/2013/0109

Keesstra SD, Bouma J, Wallinga J, Tittonell P, Smith P, Cerda A, Montanarella L, Quinton JN, Pachepsky Y, van der Putten WH, et al. 2016. The significance of soils and soil science towards realization of the United Nations Sustainable Development Goals. Soil. 2(2): 111-128.

Kim M, Gilley J E 2008 Artificial Neural Network Estimation of Soil Erosion and Nutrient Concentrations in Runoff From Land Application Areas Comput Electron Agric. doi://10.1016/j.compag.2008.05.021.

Kirkby, M.; Bracken, L. Gully processes and gully dynamics. Earth Surf. Process. Landf. J. Br. Geomorphol. Res. Group. 2009, 34, 1841-1851.

Kuhn, M., 2008. Building predictive models in R using the caret package. J. Stat. Softw. 28, 1-26.

Lee, S., Ryu, J.H., Min, K., Won, J.S., 2003. Landslide susceptibility analysis using GIS and artificial neural network. Earth Surf. Process. Landf. 28, 1361-1376.

Liaw, A., Wiener, M., 2002. Classification and regression by random forest. R. News 2 (3), 18-22.

Liu K, Ding H, Tang G, Na J, Huang X, Xue Z, Yang X, Li F. 2016. Detection of catchment-scale gullyaffected areas using unmanned aerial vehicles (UAV) on the Chinese loess plateau. ISPRS International Journal of Geo-Information 5: 238. DOI: 10.3390/ijgi5120238.

Luca F, Conforti M, Robustelli G. 2011. Comparison of GIS-based gullying susceptibility mapping using bivariate and multivariate statistics: Northern Calabria, South Italy. Geomorphology. 134(3-4):297-308. 
Magliulo, P. Assessing the susceptibility to water-induced soil erosion using a geomorphological, bivariate statistics-based approach. Environ. Earth Sci. 2012, 67, 1801-1820.

Malik I. 2008. Dating of small gully formation and establishing erosion rates in old gullies under forest by means of anatomical changes in exposed tree roots (Southern Poland). Geomorphology. 93(3-4):421436.

Marzolff, I., \& Ries, J. B. 2011. Piping as a process of gully erosion in small-format aerial photography: A short note. Cuadernos de investigación geográfica. Geographical Research Letters, (37), 115-120.

Mccloskey, G.; Wasson, R.; Boggs, G.; Douglas, M. Timing and causes of gully erosion in the riparian zone of the semi-arid tropical Victoria River, Australia: Management implications. Geomorphology 2016, 266, 96-104.

Meinen, B.U., Robinson, D.T. (2020) Mapping erosion and deposition in an agricultural landscape: Optimization of UAV image acquisition schemes for SfM-MVS. Remote Sensing of Environment, 239, 111666.

Mezaal, M.R.; Pradhan, B.; Shafri, H.; Mojaddadi, H.; Yusoff, Z. Optimized Hierarchical Rule-Based Classification for Differentiating Shallow and Deep-Seated Landslide Using High-Resolution LiDAR Data. In Global Civil Engineering Conference; Springer: Berlin, Germany, 2017.

Micheletti, N., Foresti, L., Robert, S., Leuenberger, M., Pedrazzini, A., Jaboyedoff, M., Kanevski, M., 2014. Machine learning feature selection methods for landslide susceptibility mapping. Math. Geosci. 46 (1), 33-57. https://doi.org/10.1007/ s11004-013-9511-0.

Naghibi, S.A., Pourghasemi, H.R., 2015. A comparative assessment between three machine learning models and their performance comparison by bivariate and multivariate statistical methods in groundwater potential mapping. Water Resour. Manag. 29, 5217-5236.

Nampak, H.; Pradhan, B.; Mojaddadi Rizeei, H.; Park, H.J. Assessment of Land Cover and Land Use Change Impact on Soil Loss in a Tropical Catchment by Using Multi-Temporal SPOT-5 Satellite Images and RUSLE model. Land Degrad. Dev. 2018.

Negnevitsky, M., 2002. Artificial Intelligence-A Guide to Intelligent Systems. Addison Wesley Co, Great Britain.

Pani, P. 2016. Controlling gully erosion: an analysis of land reclamation processes in Chambal Valley, India. Development in Practice, 26(8), 1047-1059. https://doi.org/10.1080/09614524.2016.1228831

Patel, P.P., Dasgupta, R., Mondal, S. 2020. Using Ground-Based Photogrammetry for Fine-Scale Gully Morphology Studies: Some Examples. In: Shit, P., Pourghasemi, H.R., Bhunia, G.S. (eds.) Gully Erosion Studies from India and Surrounding Regions. SpringerNature, Switzerland, pp. 207-220.

https://doi.org/10.1007/978-3-030-23243-6_12 
Pourghasemi HR, Yousefi S, Kornejady A, Cerda A. 2017. Performance assessment of individual and ensemble data-mining techniques for gully erosion modeling. Sci Total Environ. 609:764-775.

Prosdocimi, M., Cerdà, A., \& Tarolli, P. (2016). Soil water erosion on Mediterranean vineyards: A review. Catena, 141, 1-21.

Rahmati O, Haghizadeh A, Pourghasemi HR, Noormohamadi F. 2016. Gully erosion susceptibility mapping: the role of GIS-based bivariate statistical models and their comparison. Nat Hazards. 82(2):1231-1258.

Rahmati O, Tahmasebipour N, Haghizadeh A, Pourghasemi HR, Feizizadeh B. 2017. Evaluation of different machine learning models for predicting and mapping the susceptibility of gully erosion. Geomorphology. 298:118-137.

Ranga, V., Poesen, J., Van Rompaey, A., Pani, P. (2016) Detection and analysis of badlands dynamics in the Chambal River Valley (India), during the last 40 (1971-2010) years. Environmental Earth Sciences, 75, 183. https://doi.org/10.1007/s12665-015-5017-z

Renschler CS, Harbor J. 2002. Soil erosion assessment tools from point to regional scales - the role of geomorphologists in land management research and implementation. Geomorphology. 47(2-4):189-209.

Ripley, B., Venables, W., 2016. Package 'nnet': Feed-Forward Neural Networks and Multinomial Log-Linear Models. The R Project for Statistical Computing Available at: https://CRAN.R-project.org/package=nnet (2020-10-10).

Rizeei, H.M.; Saharkhiz, M.A.; Pradhan, B.; Ahmad, N. Soil erosion prediction based on land cover dynamics at the Semenyih watershed in Malaysia using LTM and USLE models. Geocarto Int. 2016, 31, 1158-1177.

Sadeghi-Niaraki A, Kim K, Varshosaz M. 2010. Multi-criteria decision-based model for road network process. Int J Environ Res. 4:573-582.

Sela S, Svoray T, Assouline S. 2012. Soil water content variability at the hillslope scale: impact of surface sealing. Water Resour Res. 48(3):3522.

Shruthi, R. B. V., Kerle, N., Jetten, V., Abdellah, L. \& Machmach, I. Quantifying temporal changes in gully erosion areas with object oriented analysis. Catena 128, 262-277 (2015).

Tang, W., Liu, H., Liu, B. 2013. Effects of gully erosion and gully filling on soil degradation in the black soil region of Northeast China. Journal of Mountain Science 10(5): 913-922

Therneau, T., Atkinson, B., Ripley, B., 2019. Recursive partitioning and regression trees. https://cran.rproject.org/package 1/4rpart. (Accessed 7 December 2019). Tibshirani, R., 1996. Regression Shrinkage and 
Selection via the Lasso. Journal of the Royal Statistical Society. Series B (Methodological). 58 (1), 267288.

Tsangaratos P, Benardos A. 2014. Estimating landslide susceptibility through a artificial neural network classifier. Nat Hazards. 74(3):1489-1516.

UNEP. The Emissions Gap Report. United Nations Environment Programme (UNEP) Nairobi. 2017. Available online: www.unenvironment.org/resources/emissions-gap-report (accessed on 13 October 2020).

Vorpahl, P., Elsenbeer, H., M€arker, M., Schroder, B., 2012. How can statistical models $€$ help to determine driving factors of landslides? Ecol. Model. 239, 27-39. https:// doi.org/10.1016/J.ECOLMODEL.2011.12.007.

Wu, X., Kumar, V., Ross Quinlan, J., Ghosh, J., Yang, Q., Motoda, H., Steinberg, D., 2008. Top 10 algorithms in data mining. Knowl. Inf. Syst. 14 (1), 1-37. https://doi.org/ 10.1007/s10115-007-0114-2

Yitbarek, T. W., Belliethathan, S., \& Stringer, L. C. (2012). The onsite cost of gully erosion and cost-benefit of gully rehabilitation: A case study in Ethiopia. Land Degradation \& Development, 23(2), 157-166.

Youssef, A.M., Pourghasemi, H.R., Pourtaghi, Z.S., Al-Katheeri, M.M., 2016. Landslide susceptibility mapping using random forest, boosted regression tree, classification and regression tree, and general linear models and comparison of their performance at Wadi Tayyah Basin, Asir Region, Saudi Arabia. Landslides 13 (5), 839-856. https://doi.org/10.1007/s10346-015-0614-1.

Zabihi, M.; Mirchooli, F.; Motevalli, A.; Darvishan, A.K.; Pourghasemi, H.R.; Zakeri, M.A.; Sadighi, F. Spatial modelling of gully erosion in Mazandaran Province, northern Iran. Catena 2018, 16, 1-13.

Zakerinejad, R.; Maerker, M. An integrated assessment of soil erosion dynamics with special emphasis on gully erosion in the Mazayjan basin, southwestern Iran. Nat. Hazards 2015, 79, 25-50.

Zhang, X.; Fan, J.; Liu, Q.; Xiong, D. The contribution of gully erosion to total sediment production in a small watershed in Southwest China. Phys. Geogr. 2018, 39, 246-263.

Zhu H, Tang G, Qian K, Liu H. 2014. Extraction and analysis of gully head of Loess Plateau in China based on digital elevation model. Chin Geogr Sci. 24(3):328-338.

\section{Figures}



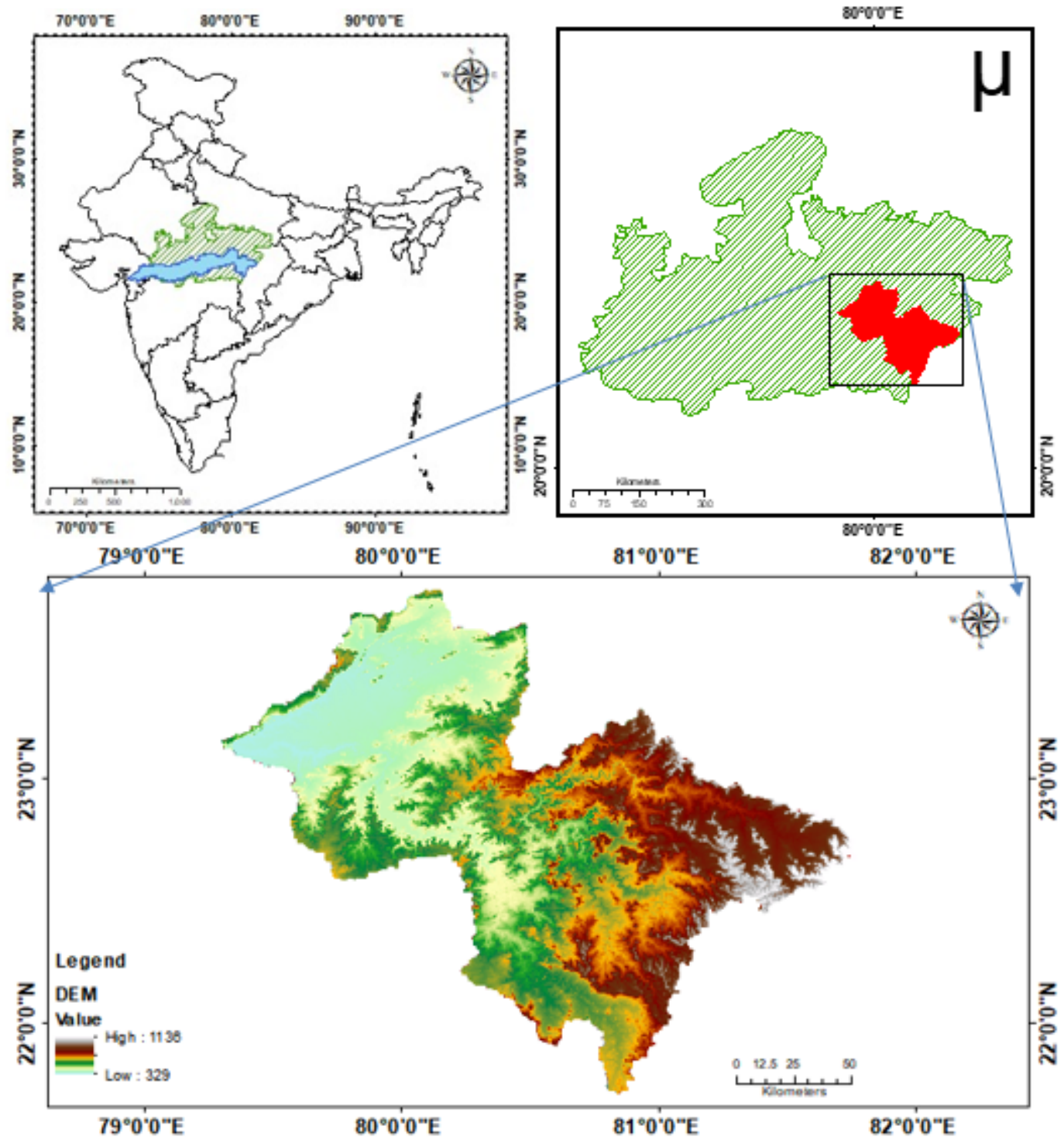

Figure 1

Location ofthe Upper Narmada River Basin in central-western India and within the state of Madhya Pradesh 


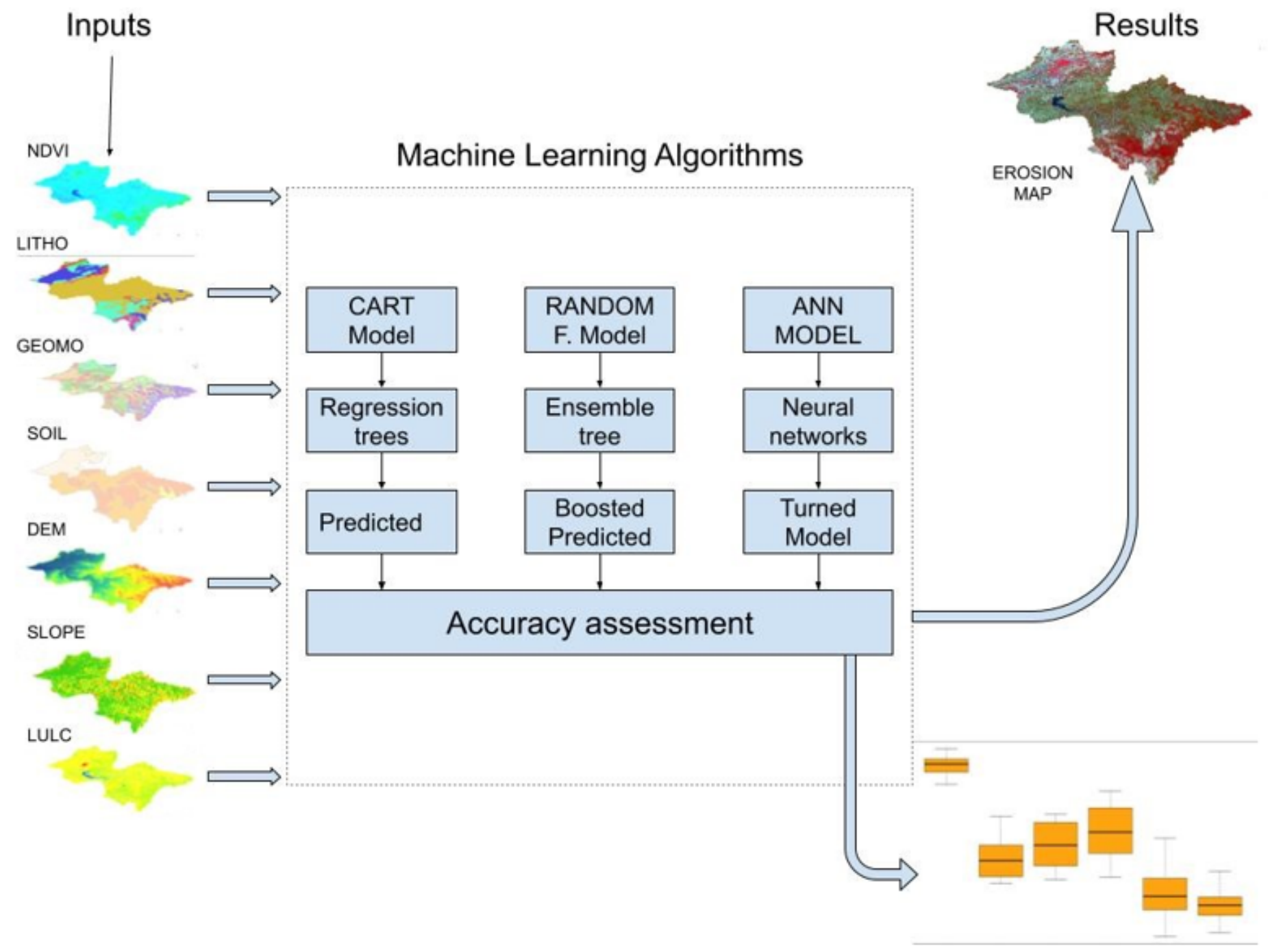

Figure 2

The flowchart of the workflow 

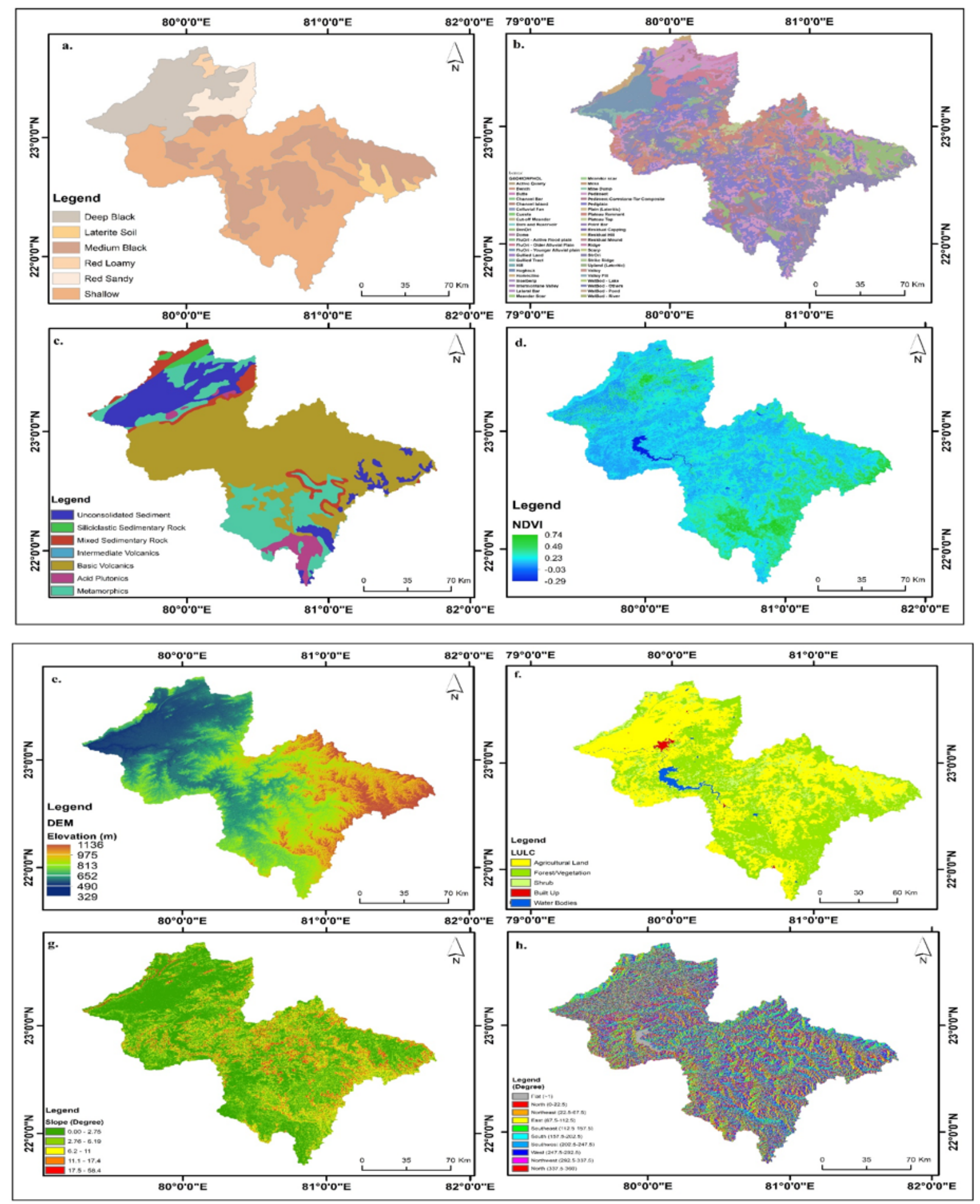

\section{Figure 3}

a. Physiographic and vegetation factors associated with gully formation- (a) Soil types, (b) Geomorphology, (c) Lithology, and (d) NDVI b. Topographic and vegetation factors associated with gully formation- (e) Elevation, (f) Land Use/Land Cover (LULC) (g) Slope, and (h) Aspect c. Hydrological and anthropogenic factors associated with gully formation- (i) Stream-road junctions and sites of existing gullies, (j) Rainfall, (k) Stream density, and (I) Road Density 


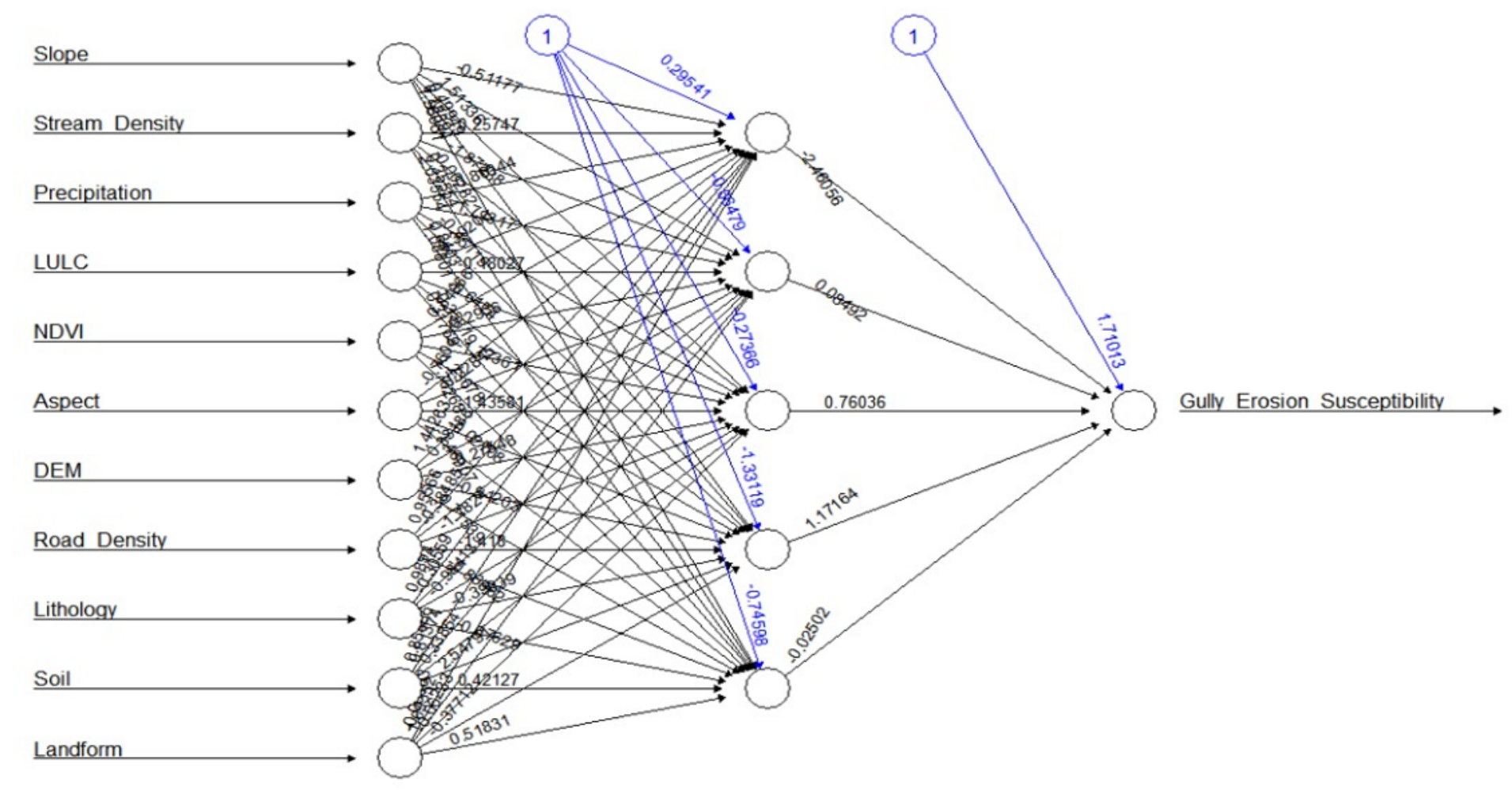

Figure 4

The spiral network of gully erosion 

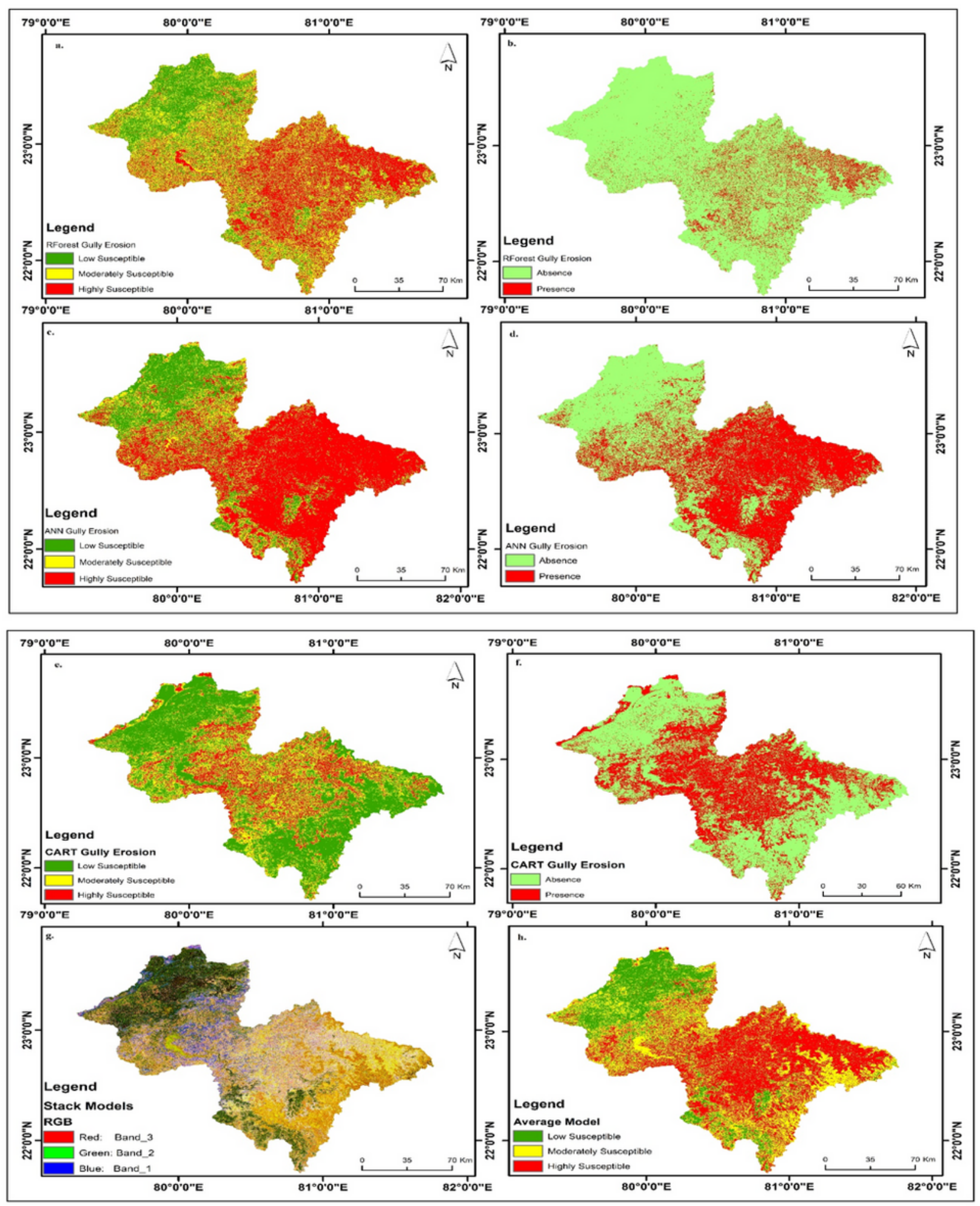

\section{Figure 5}

a. Outputs from the individual models- (a) RF-derived gully erosion classes, (b) RF-derived presence/absence of gully erosion, (c) ANN-derived gully erosion classes, (d) ANN-derived presence/absence of gully erosion Note: See Table 3 for the limits of the different susceptibility ranges. b. Outputs from the individual models- (e) CART-derived gully erosion classes, (f) CART-derived presence/absence of gully erosion, (g) Stack Model having combination of the CART, RF and ANN 
outputs, (h) Mean of all the models' outputs Note: See Table 3 for the limits of the different susceptibility ranges. In the Stack Model output, the CART model derived output layer was assigned the blue band, the RF output was assigned the green band and the ANN based output was assigned the red band.
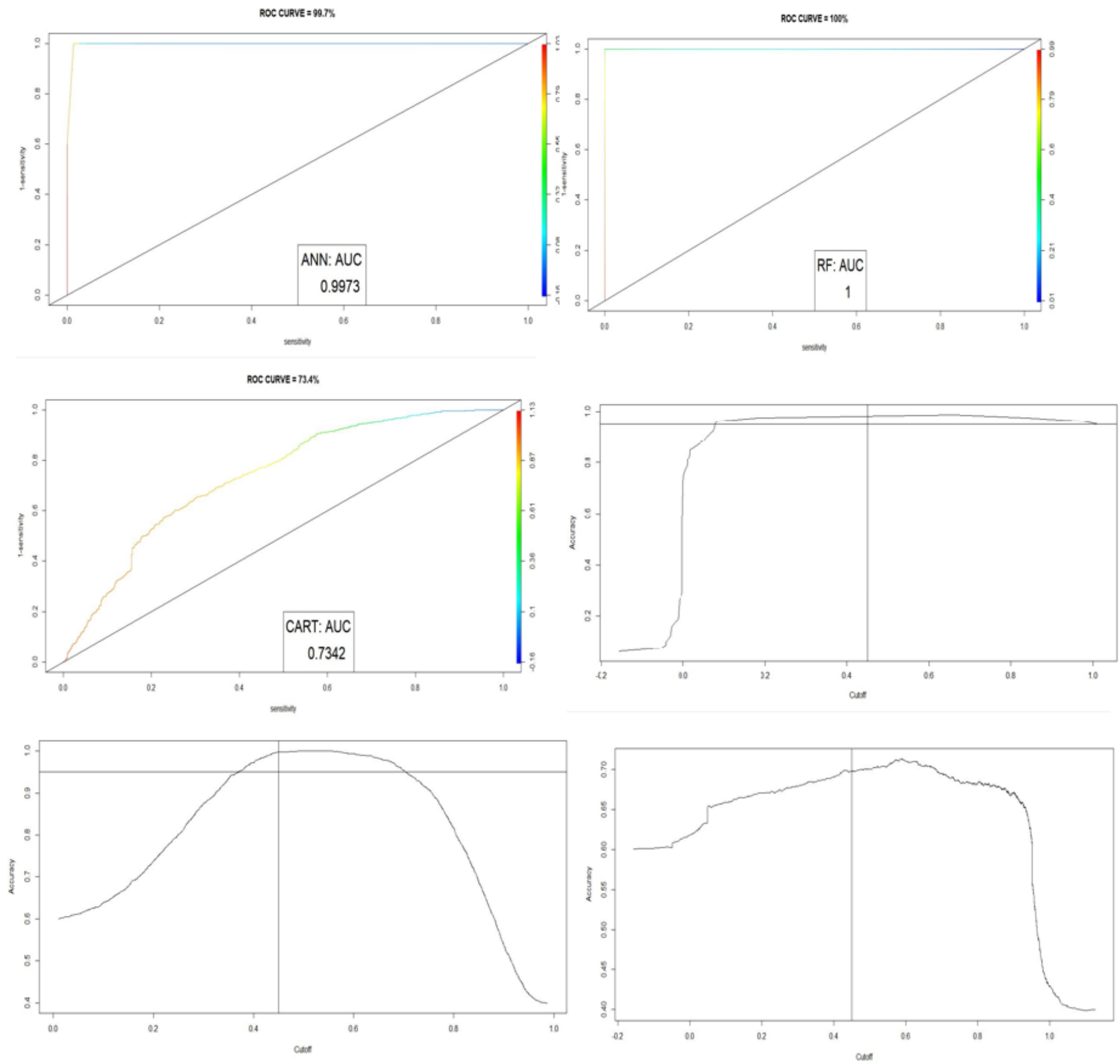

Figure 6

ROC-AUC figures for the different models 


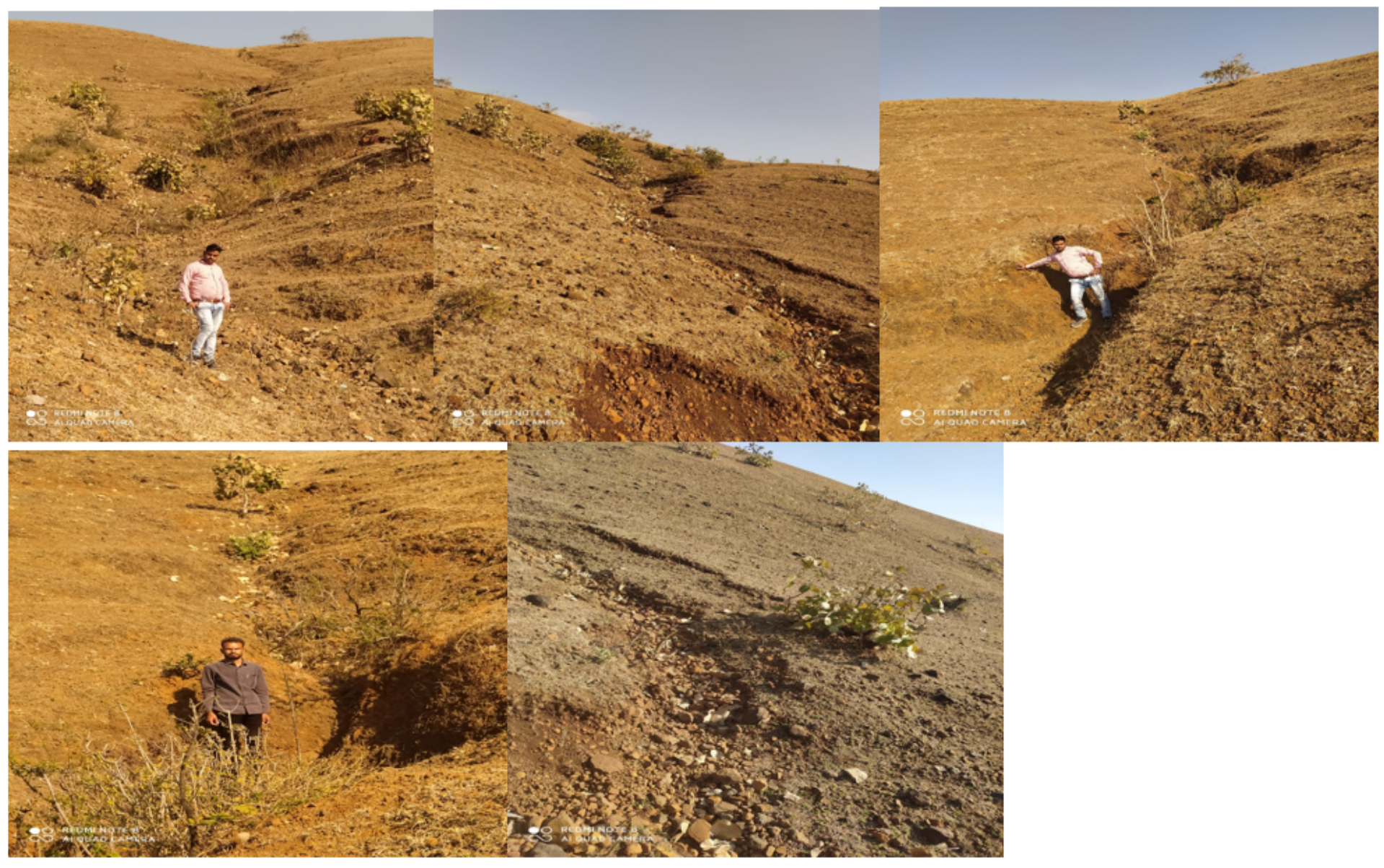

Figure 7

Sample of Gullies in the study area. 